\title{
A Statistics Based Approach for Defining Reference Trajectories on Road Sections
}

\author{
Giuseppe Cantisani ${ }^{1} \&$ Giuseppe Loprencipe ${ }^{1}$ \\ ${ }^{1}$ Department of Civil, Constructional and Environmental Engineeering, Sapienza, Università di Roma, Italy \\ Correspondence: Giuseppe Loprencipe, Department of Civil, Constructional and Environmental Engineeering, \\ Sapienza, Università di Roma, Rome, Italy. Tel: 39-6-4458-5112. E-mail: giuseppe.loprencipe@uniroma1.it
}

Received: June 28, 2013

doi:10.5539/mas.v7n9p32

\author{
Accepted: August 5, $2013 \quad$ Online Published: August 15, 2013 \\ URL: http://dx.doi.org/10.5539/mas.v7n9p32
}

\begin{abstract}
Theories and models usually adopted in designing roads, especially for safety verifications, are based on the hypothesis of a single vehicle that follows a trajectory matching with the road axle. This condition can be expressed as "road following" model and it determines many important design parameters, like curvature, design speed, superelevation, lane placement, sight distances, characteristics of transition curves, etc.. In real conditions, vehicles on a road section travel along trajectories always different from the road axle, so, in order to ensure that theoretical models can be effective, it is important to evaluate how a reference trajectory, on particular road elements, can statistically represent the population of users. In this way, it will be possible to design the road axle on the basis of this reference trajectory and consequently develop road design processes. To deal with these problems, it is useful to perform some surveys on trajectories of vehicles on real road elements, but the statistical analysis of the data needs specific procedures to extract trajectories that have a formal geometric expression and correctly represent the scattering of vehicles' position. The article presents a statistics based method, proposed with the aim to obtain the reference trajectories on road sections starting from surveys over real exercise conditions; the method was tested on case studies regarding two ramp terminals, that are particularly interesting because when the infrastructure present special geometrical or physical features the vehicle trajectories are influenced by them.
\end{abstract}

Keywords: road geometric design, trajectories, vehicles' path, lateral displacement, statistics, users' behavior

\section{Introduction}

\subsection{Geometric Design Principles and Research Trends}

The geometric design of roads and highways is traditionally based on theories and models that establish some deterministic relations between the features of infrastructure and both expected safety conditions and users' performances. The most part of design standards, adopted by road Authorities and Administrations around the world (AASHTO, 2001; VSS, 1991; IT D.M., 2001; TAC, 1999), are based on the hypothesis that a vehicle moves along a road section following a path defined by road geometry. At the same time, the design features determine the maximum safe speed that can be maintained over the section of highway and along each alignment element. The road can be conveniently represented by its longitudinal axle (roadway line) and cross sections: if the road alignment is properly defined, it almost matches with the line described by vehicle through space, that is its trajectory. The described hypothesis can be designated as the "road following" condition. In effect, according to the Green Book (AASHTO, 2001), the "Driving Task" encompasses the road-following and safe-path maintenance, in response to road and traffic conditions: these activities are in the care of road user, who perform them at a mid-level of cognitive processes that he or she carries out.

Many research works on road geometric design have focused on topics directly or indirectly related to the road-user interactions corresponding to the above reminded basic principles; the studies can be grouped in three main areas (Gibreel et al., 1999): (1) Design Speed and Operating Speed; (2) Driver Performance and Design Consistency; and (3) Safety Conditions.

Regarding to speed, the most part of studies deal with the prediction of Operating Speed: the traditional model for Design Speed on curves, that expresses the relationship between vehicle speed $\mathrm{V}$ and side friction demand $f_{R d}$ (on a curve of specified radius $R$ and superelevation $e$ ): 


$$
R=\frac{V^{2}}{127 \cdot\left(e+f_{R d}\right)}
$$

has to be complemented by new concepts referred to speed profiles (Leisch \& Leisch, 1977); since the proposed models, the Operating Speed can be identified as the 85-th percentile of vehicles speed distribution and predicted using some criteria (Lamm et al., 1988; Hassan, 2004), based on the characteristics of geometric elements (Cantisani \& Di Vito, 2012). However, other studies (Perco, 2008; Dell'Acqua, 2012) affirm that the characteristics of single alignment elements cannot to completely explain the speed choice on curves and tangents, because it also depends on the general character of the road alignment.

In the field of Driver Performance and Design Consistency, the research works in literature often assume these topics are strictly related to the major goal of highway design, that consists in achieving comfortable, efficient and safe traffic operation (Gibreel et al., 1999; De Luca \& Dell'Acqua, 2012). The Green Book, in effect, declares that the proper highway design should be founded on driver performances, because when a design is incompatible with the attributes of drivers, accidents and inefficient operations can increase. In particular, the performances of drivers are dependent on receiving and using information from road and on comparison with those already possessed by drivers. Since the 1980s, many authors have discussed basic concepts (Messer, 1980; Nicholson, 1998) and methods for calculating and evaluating the speed profiles (Fitzpatrick et al., 2000; Hassan, 2004; Cafiso, Di Graziano, \& La Cava, 2005), in order to ensure consistency and homogeneity of road alignments.

Safety Conditions may represent the fundamental theme for preventing accidents due to infrastructure failures; they derive from many geometric characteristics: cross section composition and width, horizontal and vertical alignment design, sight distances and so on. In particular, vehicle stability was focused as an essential problem, because the conventional model of (1) has some assumptions that are judged too rough and, furthermore, the effect of a vertical curve or grade has not been considered (Furtado, Easa, \& Abd El Halim, 2002). Other considerations are referred to interactions between geometric design features and safety on roads; for example, the analysis of horizontal curves (Reinfurt et al., 1991) pointed out that when curves become sharper there is a proportionally greater increase in speed reduction and edgeline encroachments on the inside lane; safety is involved because especially the centerline encroachments can favor run-off-road crashes on the inside of the curve as well as head-on and opposite direction-sideswipe crashes with oncoming vehicles.

The width of lanes, on the other hand, influences both speed and vehicle lateral placement (Neuhardt, Herrin, \& Rockwell, 1971; McLean, 1974). In effect, field studies on rural two-lane highways in free-flow conditions have shown that the interactions between roadway factors and individual (or average) driver speed selection as well as corner-cutting strategies on curves are clearly present. Also the comparison between real road conditions and simulator environment confirms these outcomes (Blana \& Golias, 2002). Moreover, the effects on road safety of lane width are not so easy to recognize: in the past, wider lanes have been assumed to be beneficial to safety because of the increase of the average separation between vehicles in adjacent lanes and for providing more room for driver correction in near-accident circumstances. Actually (Hauer, 2009), it is more correct to affirm that lane width plays a different role in single and multi-lane roads, because for single-lane roads it has a bigger influence on driver behaviour, in terms of trajectory and selected lateral position.

\subsection{Real-Road Operating Conditions}

In real conditions, vehicles on road sections travel along trajectories always different from the road axle and also, generally, from the median line of their allowed lane. In addition to the intrinsic variability of paths, due to the characteristics of road vehicles steering system, it needs to consider that the control of vehicle trajectory and the adjustment of travel speed are in the care of the driver. These actions derive by solving a complex spatio-temporal problem, that involves human skills and judgments and is mainly based on visual information acquired by the user. Misleading of the road environment and/or failures in information processing can result as human errors in driving task and can cause operating problems or road accidents. According to recent studies (Rosey \& Auberlet, 2012), the variability of trajectories and, consequently, of the lateral position in the lane indicates an inadequate guidance and incorrect paths that may increase the likelihood of accident.

More general, considering the previously discussed outcomes of the literature review, the difference between the real trajectory of a generic vehicle and the theoretical one can emphasize the safety problems related to geometric characteristics of roads. In particular, vehicle stability along curve alignments, expressed by (1), can result not certain because the formula assumes drivers have a theoretical path but that may be not true (Glennon \& Weaver, 1972). In addition, the trajectories continuously vary along each alignment element: as reported in (Bonneson et al., 2007), previous researchers found that the radius of the vehicle's tracked path is, at its sharpest 
point, equal to 0.7 to 0.9 times the highway curve radius.

So, it is important to consider: what happens if a shorter or larger radius, respect to that allowed by design Policy (for given superelevation and friction values) is chosen? Are they some criteria for evaluating, for example, how many crashes will be saved if the most part of drivers select a larger radius? An author (Hauer, 2005) affirms that «the safety of horizontal curves designed by following the Policy is simply unpremeditated. The Policy is the embodiment of tradition, judgment, intuition, and experience, not empirical evidence». So, the problem can be also seen in opposite way: considering the scattering of vehicles' trajectories and lateral positions, in a given road section, what are the safety conditions that each vehicle can rely on?

\subsection{Study Objectives}

To acquire more elements for answering to the above proposed questions, it appears necessary that a probabilistic approach has to be incorporated in the road design process. According to (Hirsh, Prashker, \& Ben-Akiva, 1986), new studies has to consider that «current practice is based on a deterministic approach whereas the factors involved in the geometric design process (e.g, speed, friction, reaction time) are stochastic in nature and vary among road users». In particular, it is important to take in account that (Hirsh, 1987) the values considered for characterizing Design or Operating Speed can be referred to the $\mathrm{n}$-th percentile (generally the 85-th) of road users, but there are many users that travel faster: for these users the Safety Conditions (or Design Consistency) criteria can result unverified. In the same way, in (1) the radius of curve and side friction factors have some distribution around their average values, due to different speed and trajectories of vehicles, that can modify the equilibrium conditions.

In other terms (Hauer, 2005), it is necessary to explore a more "rational style", in place of the "pragmatic" one, for road safety management, starting from the criteria for correct design and assessment of road geometric characteristics. Following these orientations, this paper proposes a study on vehicle dispersion in road sections aimed to recognize, on the basis of a statistical approach, the "reference trajectory" along a generic alignment element. More practical, the study deals with the problem how a reference trajectory can represent the whole population of road users; starting from the distribution of vehicles lateral displacement, in various sections along a road element, the proposed methodology assumes that the reference trajectory can be obtained as a continuous line that interpolates the points where the probability distribution reach the maximum. It is also possible to take in account the statistical distribution of displacement, in the considered sections, that gives the opportunity to observe the real exercise conditions for a proper percentile of users, in terms of distance from lateral obstacles, sight conditions, room availability (in near-accident circumstances), and so on. The proposed method was tested on case studies regarding road sections along ramp terminals, that were selected because it appears especially interesting to observe cases where the infrastructure present special geometric or physical features that influence vehicles' trajectories.

\section{Surveys on Real Road Elements}

\subsection{Surveys Method}

The knowledge of users' behavior appears essential aiming to consider the influence of human factor in the road system. The fact that speed and position of vehicles are controlled by drivers, necessarily involves the need to investigate what are the significant factors that influence users choices, decisions and actions. For these purposes, many researches have been carried out with the objective to collect experimental data about operating conditions in traffic flows and single vehicles motion (for example: Yu et al., 2011; Harlow \& Peng, 2001; Coifman et al., 1998).

Various techniques have been proposed for surveys and, in this sense, important contributions come from technology. The extraordinary advances in electronics, information and communication systems make available, today, various kinds of equipment for surveys and monitoring over vehicular traffic. According to the aims and conditions of research, various parameters can be settled with reference to the duration of surveys, the number and type of variables to collect and the availability of some monitoring technology.

A rough classification of existing techniques for data acquiring may be related to the automatism and consequently, on the basis of the need of an operator during the monitoring phase; manual measurements are really unsuitable because they require a continuous intervention of operators, while automatic systems are more efficient. These systems are generally based on the principle that the information starts from detection sensors and reaches the processing and storage unit through the transmission and the address of data. The most appropriate equipment for researches focused on vehicle trajectories and lateral displacement are, probably, the proximity sensors (like microwave radar and infrared detectors) (Cantisani, Di Vito, \& Luteri, 2012), and the 
remote monitoring sensors, like video cameras.

\subsection{Data Processing}

Among detection systems for road surveys, in particular, video sensors allows to realize some AVIP - Automatic Video Image Processing (Semertzidis et al., 2010; Song \& Tai, 2007; Laparmonpinyo \& Chitsobhuk, 2010). They are integrated systems that continuously detect the traffic scenes on a section of road and obtain traffic parameters and other interesting data. The complexity of processing methods, that are based on a computer software that manipulates and analyzes the recorded video frames, is normally balanced by the high number of useful information that can be obtained.

In their advanced configurations, the video surveying systems allow to obtain both data for traffic statistics (like traffic counts, vehicle type classification, time-frequency distribution etc.) and information about path behavior, also allowing the identification of anomalous trajectories and unusual actions or long-term path prediction (Morris \& Trivedi, 2008).

More general, the data provided by traffic monitoring systems can be presented as a set of points (like a seeding) that represent the sequence of positions assumed by a representative part of each vehicle, following its path. Linking these points (Figure 1) it is possible to obtain curves that give a continuous representation of trajectory: in this way, however, a geometric approximation about the position of vehicle between two points recorded by the monitoring system is introduced, but the error results not significant for the usual frequency sampling (especially if surveys are performed by means of video cameras.
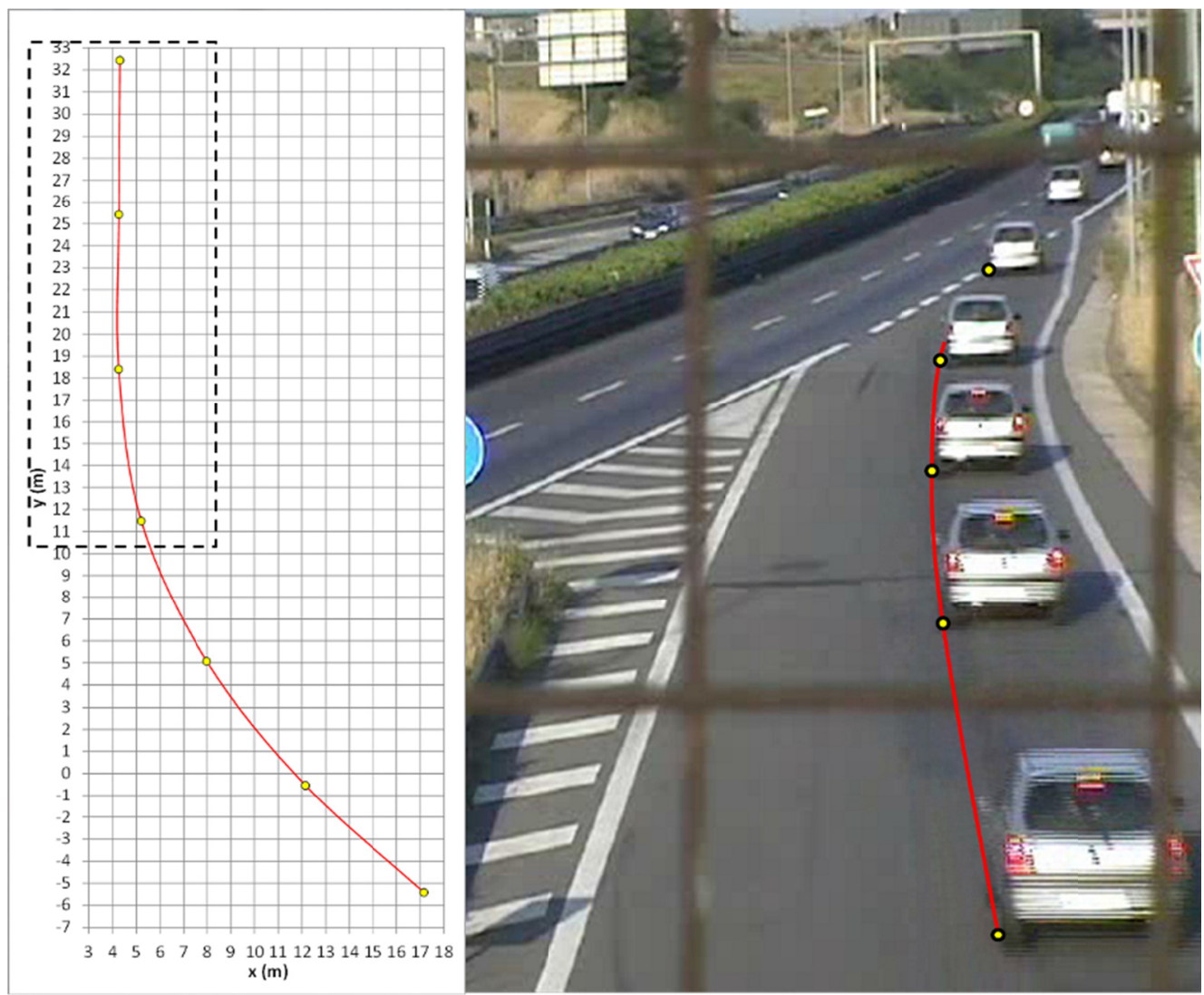

Figure 1. Example of vehicle trajectory obtained as a continuous line that interpolate a points seeding corresponding to a part of vehicle (the left rear tyre)

In addition, it is possible to obtain the distributions of lateral vehicle displacements (Figure 2), in each point along the road element, as the intersection of trajectories with a cross section line. 


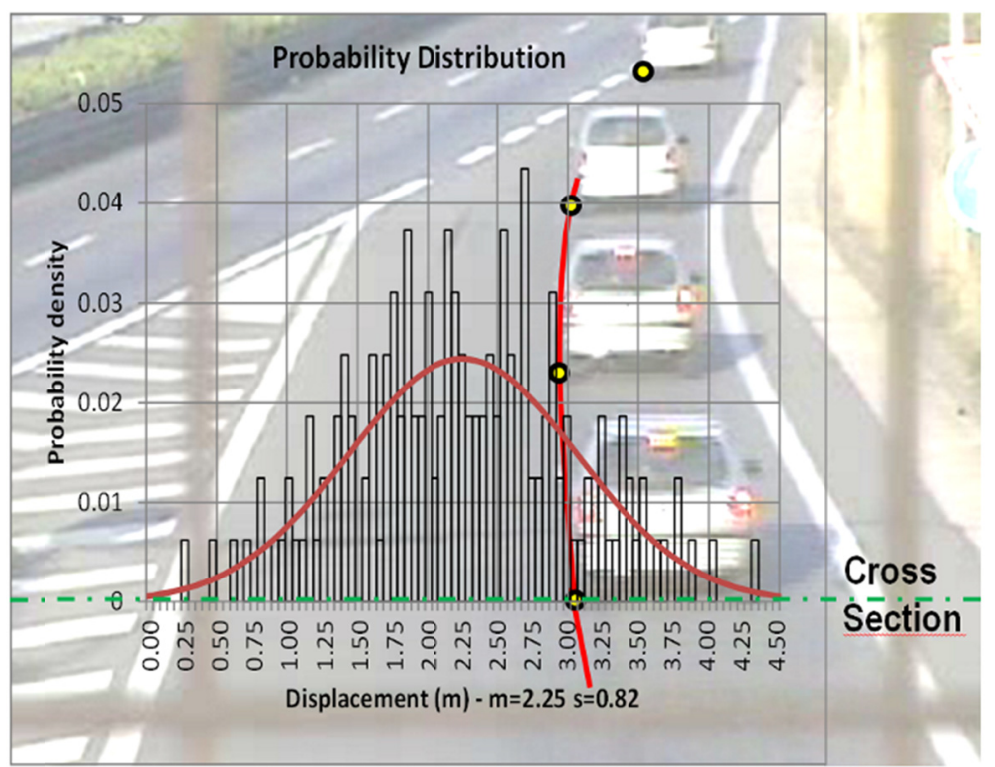

Figure 2. Distribution of vehicle displacement obtained by crossing the observed trajectories with a line section

Among the most important problems that occur when a video monitoring system is used for surveys on vehicle positions and road trajectories, as well as speed or acceleration, there is the necessity to provide coordinate conversion, for example on the basis of homologic transformations (Wei et al., 2005; García \& Romero, 2009). This problem appears especially important when coordinates of tracked paths are used to determine a reference trajectory, with the meaning above presented.

\section{Proposed Procedure}

\subsection{Analysis of Vehicles Displacement in Cross Sections}

The study was carried out starting from data on vehicle trajectories, obtained by video cameras, and extracting the distribution of lateral displacement as previously described. The intersection between cross section lines along a road element and curves representing the trajectories of vehicles belonging to the observed sample, in fact, provides the positions of vehicles when they passed through the selected sections. In this way, the displacement distribution was characterized for a certain number of sections.

Data about vehicles' displacement in the analyzed cross sections can be statistically interpreted; in particular, if they present a normal distribution, it is possible to individuate the mean as the value that corresponds to a point, in the section, where the probability a vehicle exactly passes there reaches the maximum. At the same time other statistical parameters (like standard deviation, etc.) can allow to establish where are the points related to some characteristics percentiles, with reference to the probability that vehicles, passing through the analyzed sections, fall into the space included between these points (see Figure 6).

\subsection{Construction of Continuous Reference Trajectory}

The means of statistical distributions, representing vehicles' displacement in selected sections along a road element, have the meaning previously indicated, that is the maximum probability to find a passing vehicle in these points. Consequently, it appears clear that a reference trajectory, useful to statistically represent the whole population of vehicular traffic, has to link these points of maximum probability. However, the problem is that the sections give rise to a discrete series of points while the trajectory has to be a continuous line. If the line that joins the points (two by two) is a sequence of straight segments, some important properties (as the curvature and $\mathrm{n}$-th order derivative) are not available for the design analyses to perform. Some examples of possible, but not optimal, solutions are shown in Figure 3. 


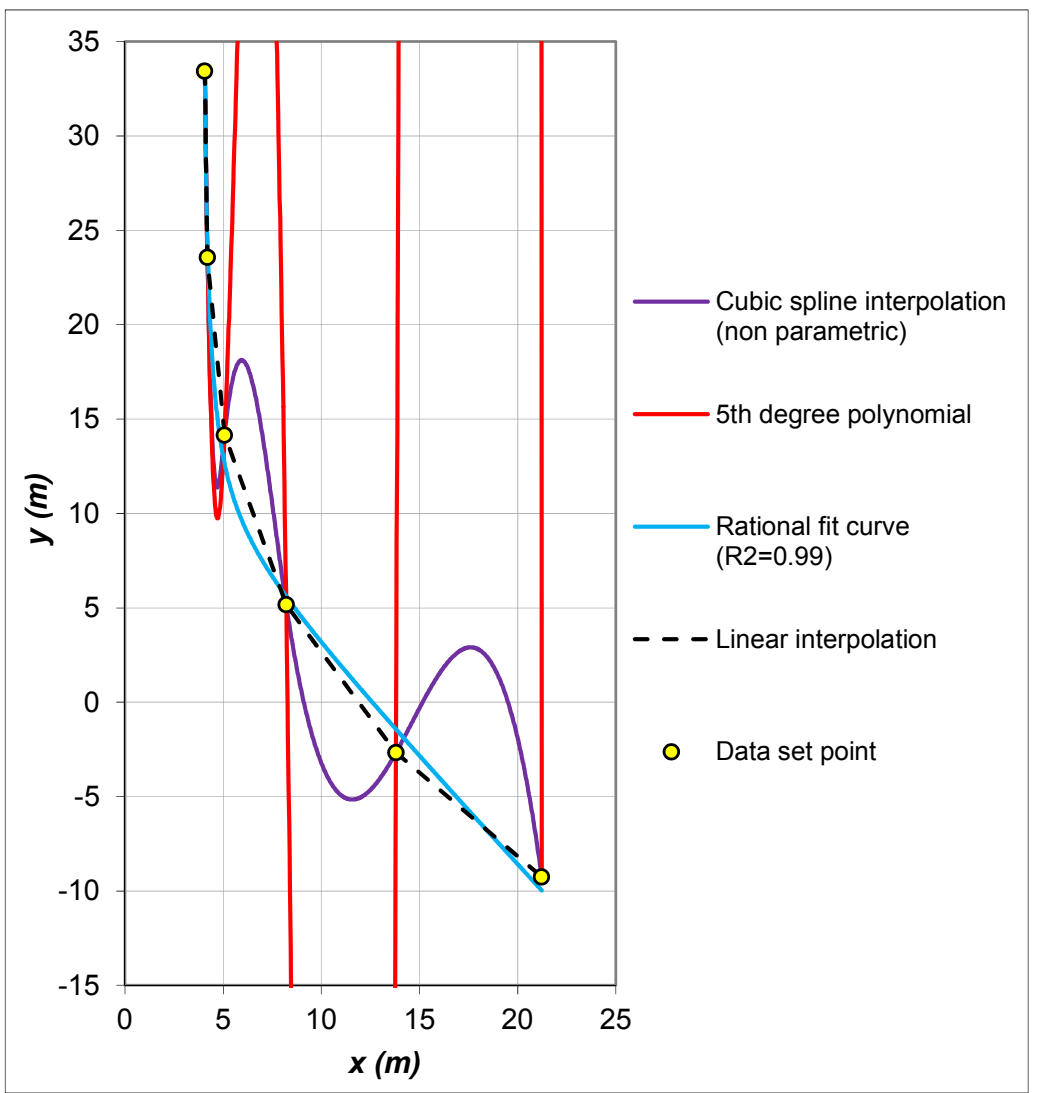

Figure 3. Examples of possible problems occurring when a discrete series of points is linked by some continuous trajectory lines

The choice of the linking curve should be made according to the following conditions:

1) The curve should interpolate the points; so, all the fitting curves should be rejected because they introduce variations in the position of maximum probability points, changing the statistical significance of the reference lines.

2) The curve should be derivable and maintain a continuity of order at least equal to 2 , in order to satisfy the real variation of the kinematic properties related to the motion of the vehicle (acceleration, jerk, etc.);

3 ) For a generic point $i$, its previous $i-1$ and its subsequent $i+1$ there should be no sign changes in the value of the curvature $\rho=1 / R$.

For these reasons it is necessary to establish and develop a method, useful to obtain a continuous curve that joins the discrete series of maximum probability points, so maintaining the statistical meaning of reference trajectory. In the present study, an early approach was that to use some Cubic Splines. Splines are cubic polynomial functions, that adapt by pieces to the interpolation points, of such way, that between pairs of contiguous points there are different polynomials. The Figure 3 shows the Cubic Spline Interpolation calculated with reference to traditional method; this method consists in the use of a "nonparametric" form of cubic polynomial functions $(y=f(x))$. In this case, for the interpolation, the independent variable is assumed as final value of $y$ with the breakpoints defined by $x$.

Given in the range $[a, b]$ a set of data nodes $a=x_{0}<x_{1}<x_{2}<\cdots<x_{n}=b$, a cubic spline interpolation (Figure 4), $S$, satisfies the following conditions:

- $\quad S$ is a cubic polynomial, $S_{j}$ on $\left[x_{j}, x_{j+1}\right]$ for $j=0,1, \ldots, n-1$.

- $S\left(x_{j}\right)=f\left(x_{j}\right)$ for $j=0,1, \ldots, \mathrm{n}$.

- $\quad S_{j+1}\left(x_{j+1}\right)=S_{j}\left(x_{j+1}\right)$ for $j=0,1, \ldots, n-2$.

- $S_{j+l}^{\prime}\left(x_{j+1}\right)=S_{j}^{\prime}\left(x_{j+1}\right)$ for $j=0,1, \ldots, n-2$.

- $\quad S^{\prime \prime}{ }_{j+l}\left(x_{j+l}\right)=S_{j}\left(x_{j+l}\right)$ for $j=0,1, \ldots, n-2$. 
- In addition, one of the following boundary conditions is satisfied:

○ $S$ " $\left(x_{0}\right)=S$ " $\left(x_{n}\right)=0$ (named "natural"; the curvature at the end is null).

○ $S^{\prime}\left(x_{0}\right)=f^{\prime}\left(x_{0}\right)$ and $S^{\prime}\left(x_{n}\right)=f^{\prime}\left(x_{n}\right)$ (named "clamped"; the values $f^{\prime}\left(x_{0}\right)$ and $f^{\prime}\left(x_{n}\right)$ should be given).

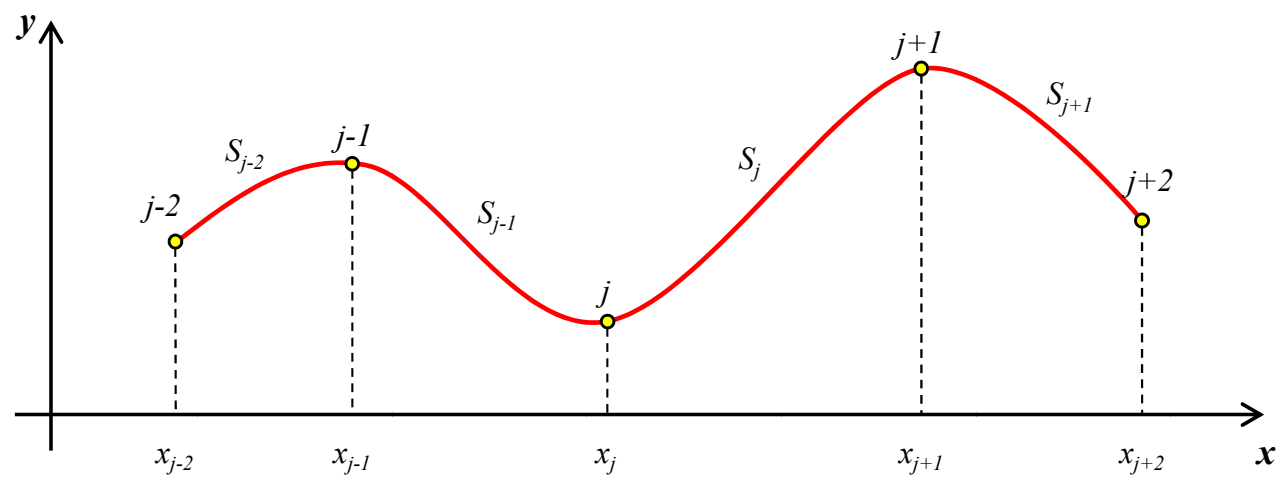

Figure 4. Cubic spline interpolation using polynomials functions $y=f(x)$

However, after the preliminary stage of research, it was considered that this method, although widely adopted in many fields of research (Giuliani, 2010) and consistent with all required features, does not fit well to the case of the trajectories of vehicles, because in this case both variables ( $x$ and $y$ ) should be considered independent (Di Mascio et al., 2012).

Afterward, another method based on the use of Hermite interpolation (Barsky, Bartels, \& Beatty, 1987) was tried. It is a theoretical approach very similar to the just described cubic spline interpolation; the only difference is the use of parametric functions for defining the interpolating polynomial. For each piece $S_{i}(u)\left[x_{i}(u), y_{i}(u)\right]$, between each pair of known data points (Figure 5), the parametric cubic polynomial expressions can be written as follows:

$$
\begin{aligned}
& x_{i}(u)=a_{x, i} u^{3}+b_{x, i} u^{2}+c_{x, i} u+d_{x, i} \quad \text { with } u \in[0 ; 1] \text { and } i=0,1,2, \ldots, n-1 \\
& y_{i}(u)=a_{y, i} u^{3}+b_{y, i} u^{2}+c_{y, i} u+d_{y, i}
\end{aligned}
$$
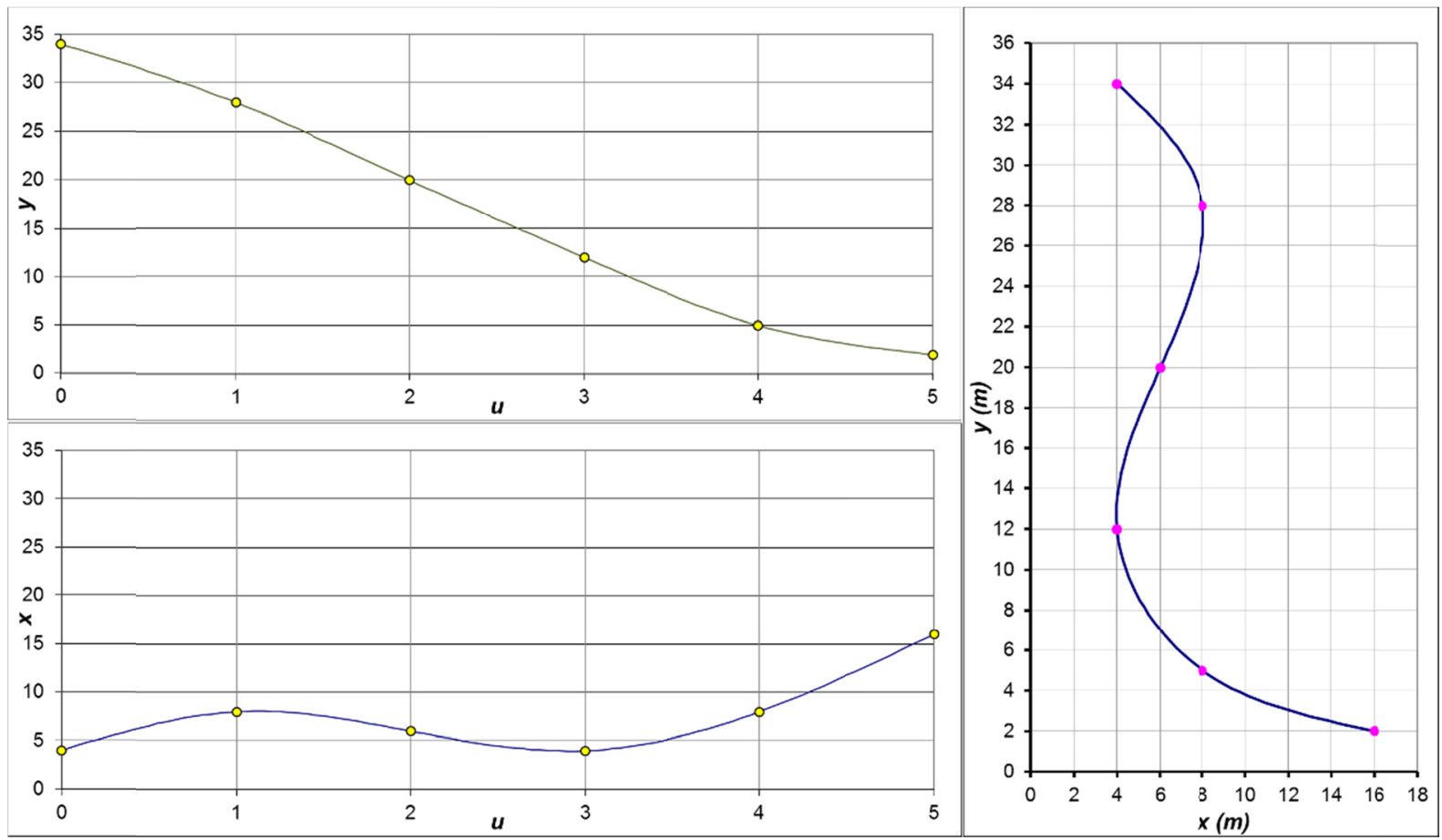

Figure 5. Cubic spline interpolation using polynomials parametric functions $x=x(u), y=y(u)$ 
For $n+1$ control points given in the plane $(x, y)$, interpolated by $n$ cubic polynomial pieces, $4 \cdot 2=8$ coefficients are requested to define each piece, therefore $8 \cdot n$ coefficients should be determined $(4 \cdot n$ coefficients for each $x(u)$ and $y(u)$ parametric function).

The available equations (for each $x$ and $y$ variable) are the following:

- $\quad 2 \cdot n$ equations for each piece passing through each pair of adjacent control points;

- $\quad(n-1)$ equations for first derivative continuity in contact points ( $\mathrm{C}^{1}$ continuity);

- $\quad(n-1)$ equations for second derivative continuity in contact points ( $\mathrm{C}^{2}$ continuity).

The total equation count is $4 \cdot n-2(8 \cdot n-4$ in total) while the needed equations is $4 \cdot n(8 \cdot n$ in total).

To obtain the other 2 equations ( 4 in total) it is necessary to set tangent and/or curvature values at the first and at the last control points, through first and/or second parametric derivative value. The system of equations can be expressed through control points coordinates, first and second derivative of the $n-1$ internal and the 2 external control points.

In this way, for the $i^{\text {th }}$ polynomial piece of the curve in any one of the parametric plane $(u, x$ or $u, y)$, the equations are, for example considering the variable $y$ (the same for $x$ ):

$$
\begin{aligned}
& Y_{i}(0)=a_{y, i}=y_{i-1} \\
& Y_{i}(1)=a_{y, i}+b_{y, i}+c_{y, i}+d_{y, i}=y_{i}
\end{aligned}
$$

and the equations expressing the first derivative at the beginning $\left(D_{y, i-1}\right)$ and at the end $\left(D_{y, i}\right)$ of $i^{\text {th }}$ polynomial segments are:

$$
\begin{aligned}
& Y_{i}^{\prime}(0)=c_{y, i}=D_{y, i-1} \\
& Y_{i}^{\prime}(1)=3 \cdot a_{y, i}+2 \cdot b_{y, i}+c_{y, i}=D_{y, i}
\end{aligned}
$$

In the Equations (3) and (4), $y_{i-1}, y_{i}, D_{y, i-1}$ and $D_{y, i}$ are respectively the control points coordinates and the first derivative value (at the beginning and at the end of $i^{\text {th }}$ piece). From Equations (3) and (4) it is possible to obtain algebraic expressions of coefficients:

$$
\begin{aligned}
& d_{y, i}=y_{i-1} \\
& c_{y, i}=D_{y, i-1} \\
& b_{y, i}=3 \cdot\left(y_{i}-y_{i-1}\right)-2 \cdot D_{y, i-1}-D_{y, i} \\
& a_{y, i}=2 \cdot\left(y_{i-1}-y_{i}\right)+D_{y, i-1}+D_{y, i}
\end{aligned}
$$

$\mathrm{C}^{2}$ continuity is obtained with the following second derivative conditions in the $n-1$ internal control points:

$$
Y_{i}{ }_{i}(1)=Y^{\prime \prime+l}(0), \text { with } i=1,2, \ldots, n ;
$$

substituting in (6) the expressions of second derivative of curve:

$$
6 \cdot a_{y, i}+2 \cdot b_{y, i}=2 \cdot b_{y, i+1}
$$

for the (5):

$$
2 \cdot\left[3 \cdot\left(y_{i}-y_{i-1}\right)-2 \cdot D_{i-1}-D_{i}\right]+6 \cdot\left[2 \cdot\left(y_{i-1}-y_{i}\right)+D_{i-1}+D_{i}\right]=2 \cdot\left[3 \cdot\left(y_{i+1}-y_{i}\right)-2 \cdot D_{i}-D_{i+1}\right]
$$

and, simplifying:

$$
D_{i-1}+4 \cdot D_{i}+D_{i+1}=3 \cdot\left(y_{i+1}-y_{i-1}\right)
$$

If the second derivative at the endpoints is equal to zero, the "natural" cubic spline is obtained. For the beginning piece of curve $(i=0)$ :

$$
2 \cdot b_{y, 1}=0
$$

and for the (5):

$$
2 \cdot\left[3 \cdot\left(y_{1}-y_{0}\right)-2 \cdot D_{y, 0}-D_{y, 1}\right]=0
$$

Simplifying:

$$
2 \cdot D_{y, 0}+D_{y, 1}=3 \cdot\left(y_{1}-y_{0}\right)
$$

Similarly, for the final piece of curve $(i=n-1)$ : 


$$
D_{y, n}+2 \cdot D_{y, n}=3 \cdot\left(y_{n}-y_{n-1}\right)
$$

The equations (9), (12) and (13) can be collected in matrix form and the $n+1$ unknowns $\mathbf{D}_{\mathbf{y}}=\left[D_{y, 0}, D_{y, 1}, \ldots, D_{y, n}\right]$ (and similarly $\mathbf{D}_{\mathbf{x}}$ for $x$ variable) can be calculated by inverting the tridiagonal matrix $\mathbf{H}$ (Cantisani et al., 2004):

$$
\left[\begin{array}{cccccccc}
2 & 1 & & & & & \\
1 & 4 & 1 & & & & & \\
& 1 & 4 & 1 & & & \\
& & 1 & 4 & 1 & & \\
& & & \cdot & \cdot & \cdot & & \\
& & & & \cdot & \cdot & \cdot & \\
& & & & 1 & 4 & 1 \\
& & & & & & 1 & 2
\end{array}\right] \cdot\left[\begin{array}{c}
D_{y, 0} \\
D_{y, 1} \\
D_{y, 2} \\
D_{y, 3} \\
\cdot \\
\cdot \\
D_{y, n-1} \\
D_{y, n}
\end{array}\right]=\left[\begin{array}{c}
3\left(y_{1}-y_{0}\right) \\
3\left(y_{2}-y_{0}\right) \\
3\left(y_{3}-y_{1}\right) \\
3\left(y_{4}-y_{2}\right) \\
\\
\\
3\left(y_{n}-y_{n-2}\right) \\
3\left(y_{n}-y_{n-1}\right)
\end{array}\right]=\mathbf{H} \times \mathbf{D}_{\mathbf{y}}=\mathbf{Y} \Rightarrow \mathbf{D}_{\mathbf{y}}=\mathbf{H}^{-1} \times \mathbf{Y}
$$

By means of (5) the algebraic coefficients of parametric expressions (2) for all polynomial segments of curve can be calculated for $x$ and for $y$; when these coefficients are settled, the entire cubic spline interpolation can be determined. The values of $1^{\text {st }}$ and $2^{\text {nd }}$ derivatives of $x$ and $y$, with respect to the parameter $u\left(x^{u}, x^{u u}, y^{u}, y^{u u}\right)$, allow to easily calculate the value of the curvature at each point of the curve:

$$
\rho=\frac{1}{R}=\frac{x^{u} \cdot y^{u u}-x^{u u} \cdot y^{u}}{\left[\left(x^{u}\right)^{2}+\left(y^{u}\right)^{2}\right]^{3 / 2}}
$$

\subsection{Other Statistical Properties}

The distributions of transversal displacements, obtained by crossing the observed sample of vehicular trajectories with section lines, also present other interesting statistical properties. The shape of a normal distribution is characterized by its mean $\mu$ and standard deviation $\sigma$. In the examined case, in particular, higher or lower values of $\sigma$ indicate a corresponding greater or smaller dispersion of trajectories passing the considered section. According to various studies in literature, for example (Blana \& Golias, 2002), differences in mean and standard deviation values, between different sections, can be correlate to the elements that influence driving task; in particular it seems that these statistical parameters indicate points where lateral position could result more or less confined because of poor road geometry and visibility.

The standard deviation values can be used also in order to perform some technical verification, following a statistics based approach; in this way, some functional or safety conditions for a certain percentile of users can be verified. Considering that (Figure 6) for a sample of data normally distributed, about $68 \%$ of values fall into the interval $[\mu-\sigma, \mu+\sigma]$, about $95 \%$ into the interval $[\mu-2 \sigma, \mu+2 \sigma]$ and about $99.7 \%$ into the interval $[\mu-3 \sigma, \mu+3 \sigma]-$ that is the empirical 68-95-99.7 rule - it is possible to perform the design verifications (or safety assessment of existing roads) for corresponding users percentiles. As an example, important features for safety and efficiency of roads, like distances from lateral obstacles, sight conditions, room availability, and so on, can be observed with reference to the statistical distributions (see Figure 7).

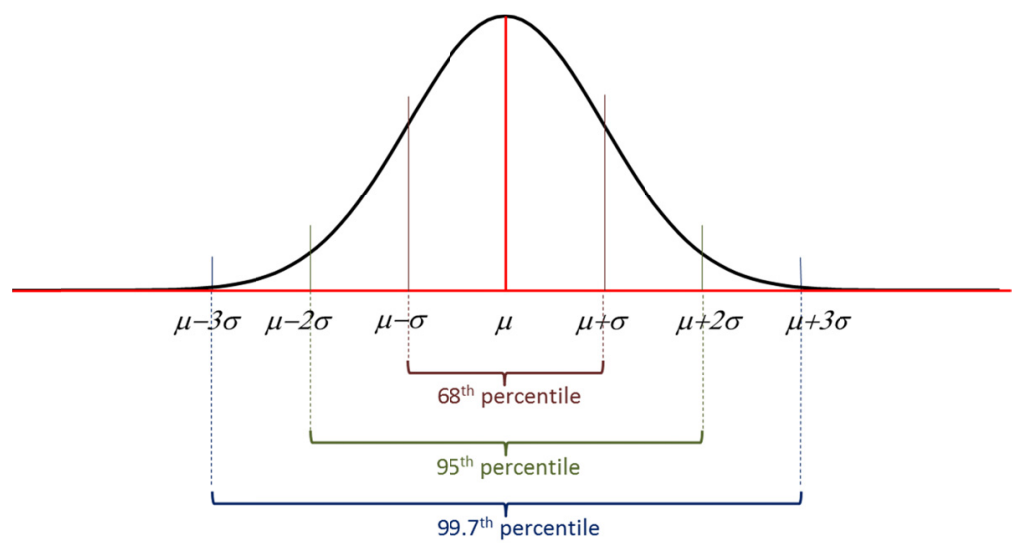

Figure 6. Percentiles of population falling into the characteristics intervals for the 69-95-99.7 rule 


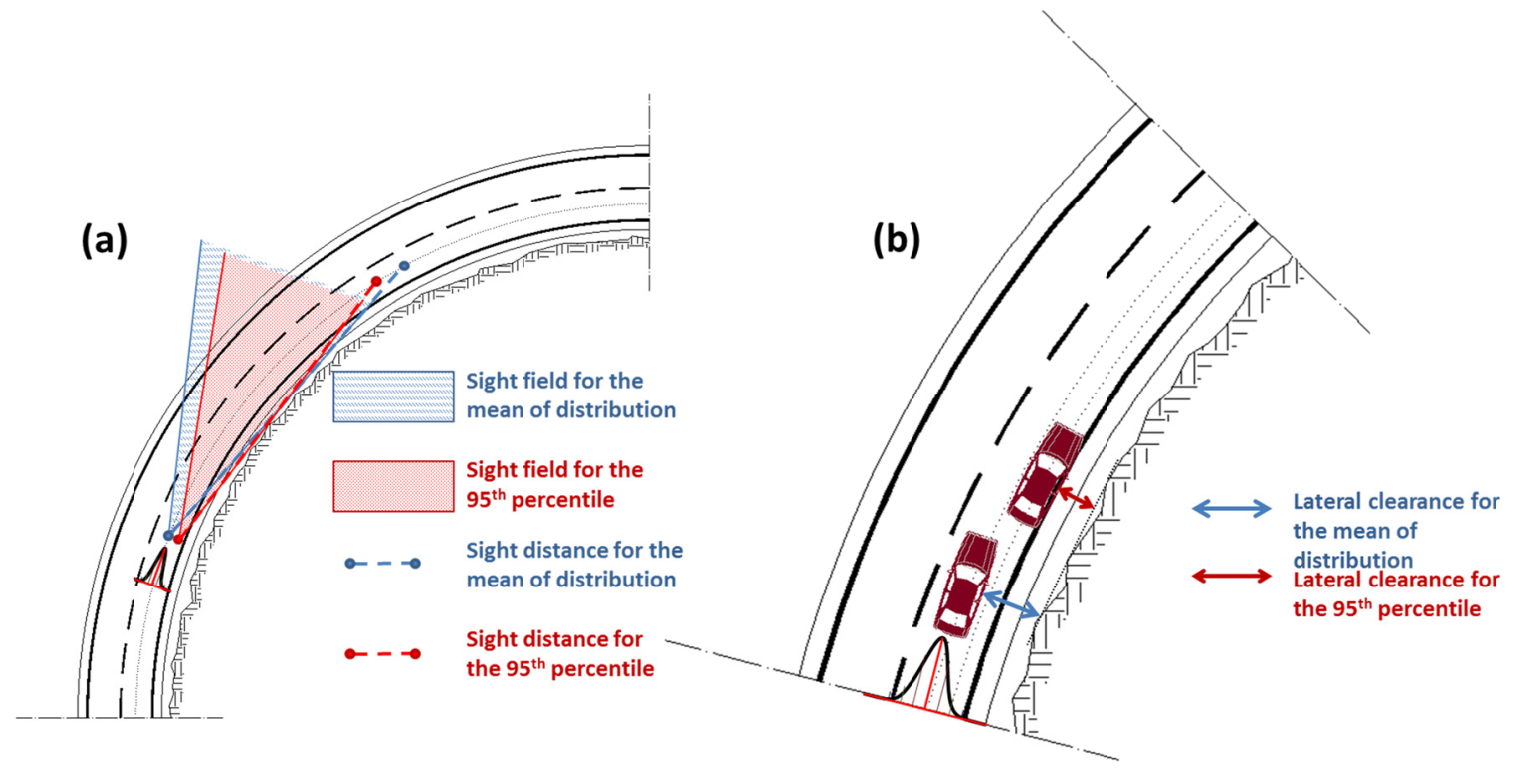

Figure 7. (a) Sight distance and sight field for the mean and for the $95^{\text {th }}$ percentile of users. (b) Lateral clearance for the mean and for the $95^{\text {th }}$ percentile of users

\section{Case Studies}

With the aim to evaluate the effectiveness and practicality of proposed approach, the methodology above presented was applied to two case studies, using the data acquired during a previous research (Bonin et al., 2003). The examples regard, in particular, the vehicles trajectories along ramp terminals; this condition was considered very interesting because when geometrical or physical features of infrastructures-like in the case of ramp terminals, sharp curves, narrow lanes, urban intersections (Cantisani, Loprencipe, \& Primieri, 2011), etc.-influence the users behavior (Mauro \& Guerrieri, 2012; Granà, Giuffrè, \& Marino, 2012), especially in terms of trajectory choice, it appears really useful to characterize reference trajectories and to evaluate statistical distributions of users' population.

The first case regards a section of about $150 \mathrm{~m}$ long ramp terminal Figure 8, which presents a straight alignment and a descending grade. There are some significant physical constraints (walls, barriers, etc.). The ramp terminal merges into a two-lane urban street located in Rome.

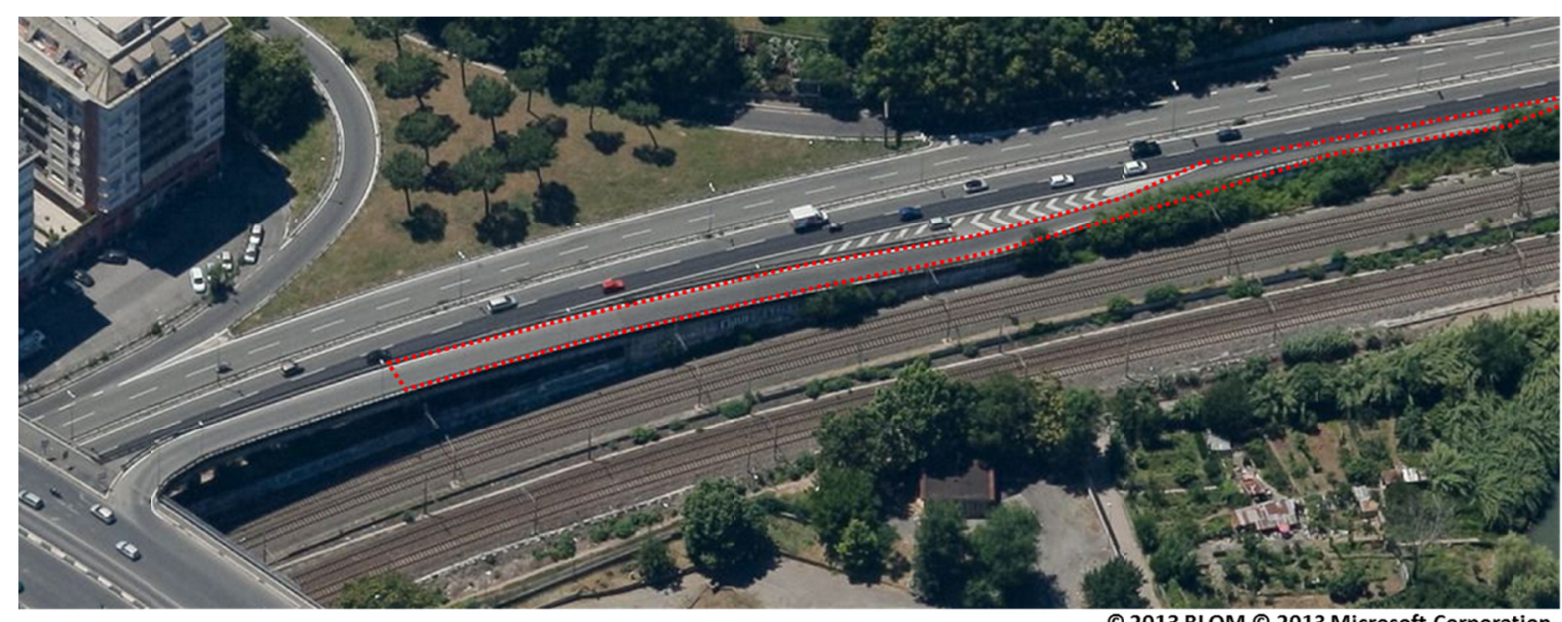

Figure 8 . View of ramp terminal (first case study)

A set of nine cross sections was considered to study the dispersion of about 100 vehicles' trajectories in free flow traffic conditions; the coordinates were preliminarily converted by means of homologic transformations. The 
sections were chosen equidistant because this situation is ideal to apply the proposed interpolation method. In each considered section, the vehicles' displacements data were checked with the Kolmogorov-Smirnov test, with the aim to verify if the samples have normal probability distribution; afterward, means and standard deviations values were calculated.

The points of maximum probability, that are the means of distributions, were interpolated with a curve "in pieces" (Hermite Parametric Cubic Spline, see Figure 9).

The coefficients of the pieces of curve determine its geometric features and other interesting properties; for example, analyzing the curvature, it is possible to detect the minimum radius (in this case equal to $360 \mathrm{~m}$ ), useful for dynamic equilibrium verification with allowed speed (see (1)).
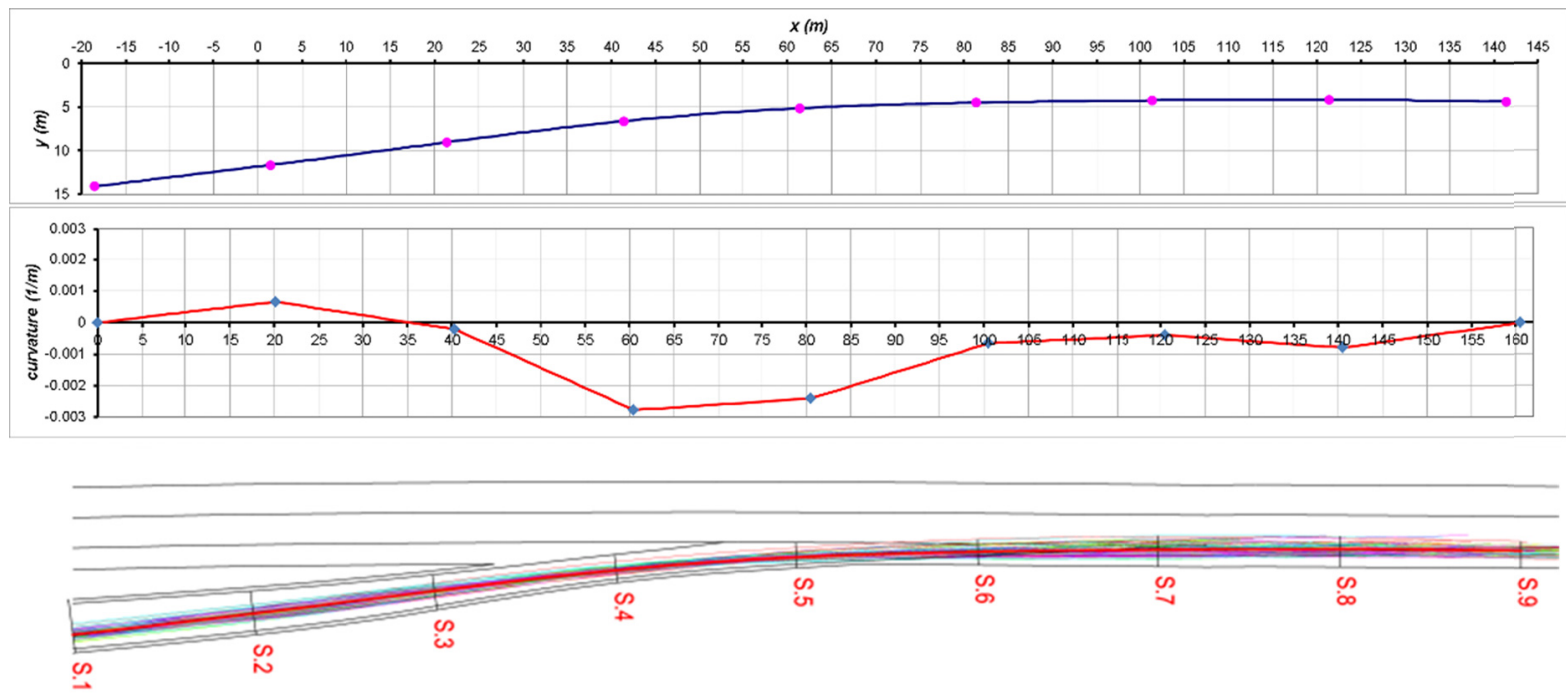

Figure 9. Cubic spline interpolation of maximum probability points (reference trajectory), curvature diagram and ramp terminal layout, with the indication of cross sections and vehicle paths

The second case study regards a section of $50 \mathrm{~m}$ long ramp terminal (Figure 10) which has curved alignment and descending grade; the terminal merges into a two-lane urban street located in Rome.

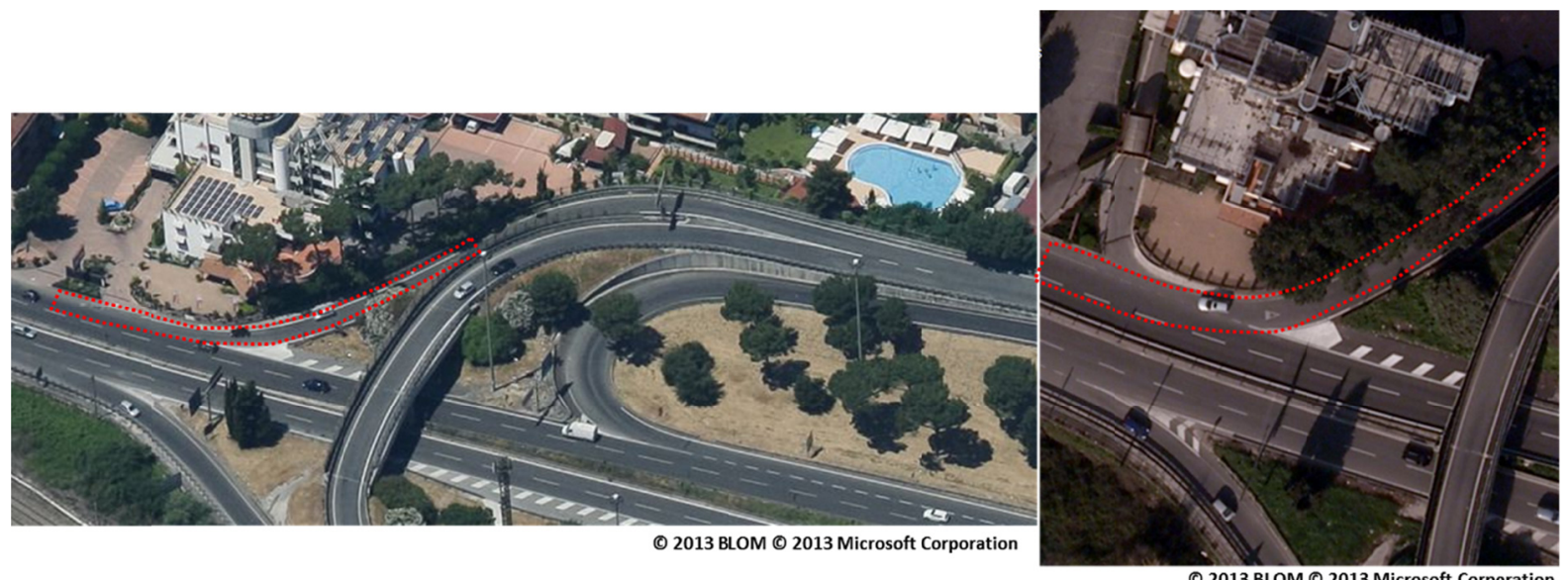

Figure 10. View of ramp terminal (second case study)

About 160 vehicles trajectories were detected and their displacements were analyzed in six equidistant cross sections, after the coordinates conversion by homologic transformations. The Kolmogorov-Smirnov test show that the sample data were normally distributed only in four sections; in any case the maximum probability points of displacements were interpolated with parametric cubic splines. 
The analysis of curvature profile show a different value of minimum radius along the reference trajectory $\left(R_{\min }=36 \mathrm{~m}\right)$ repect to that of road axle $(R=24 \mathrm{~m})$.

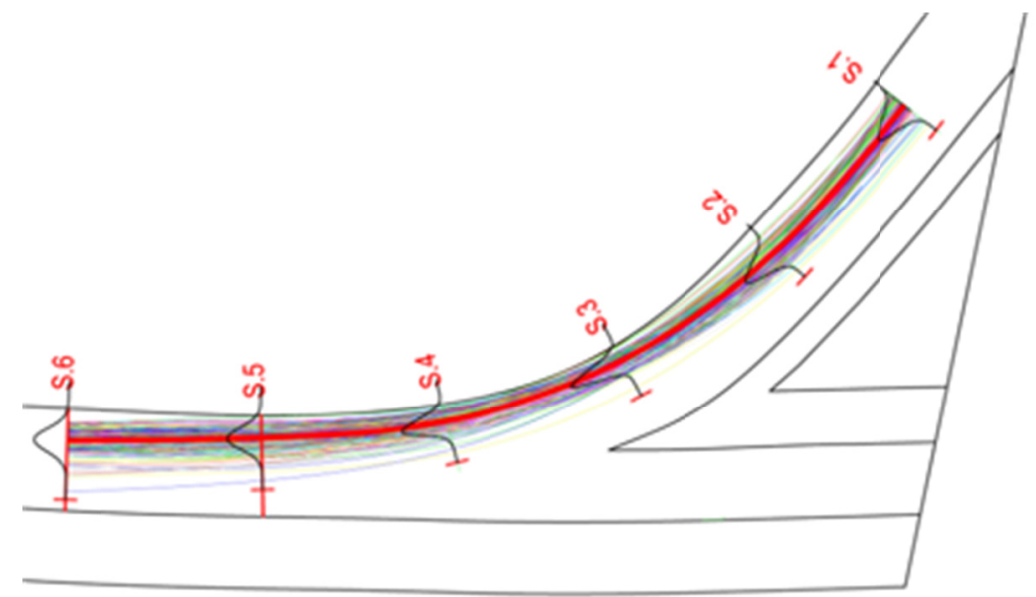

Figure 11. The ramp terminal layout of the second case study; cross sections, recorded paths, reference trajectory (cubic spline interpolation) and probability distributions are shown

\section{Conclusions}

The identification of reference trajectories, that can statistically represent vehicles' paths along road sections, has to be considered as a primary problem to address road design processes and to evaluate safety and functional conditions in the road context. The real-road operating conditions, in fact, can significantly differ from those assumed by theoretical and conventional models, usually adopted in road standards and Policies. This consideration can be referred both to the lines described by vehicles during their motion and to their lateral displacement in each point of a road section.

Using the data collected on existing road elements, by means of monitoring systems and automatic elaboration processes, it is possible to consider the statistical properties of observed samples, consisting in a certain number of vehicles' trajectories. They can be analyzed, in particular, with the aim to observe the distribution of lateral displacement in each cross section along a road element; in this way, the reference trajectories can be obtained as the lines that continuously interpolate the points where the probability to find a vehicle, when it passes through each cross line section, reaches the maximum. At the same time, in these sections, it will be possible to consider other statistical properties, like the shape of distribution and its parameters (standard deviation, etc.) and use them for safety or performance verifications.

A problem arises because when the observed trajectories are crossed by section lines, the maximum probability points (that are the means, in each section, of the probability distributions) constitute a discrete series of points, while the trajectory has to be a continuous line with a formal geometric expression. In addition, to study dynamics and kinematics of vehicle's motion (acceleration, jerk, etc.), the reference curves have to be derivable and maintain a continuity of order at least equal to 2 .

In this research, various possible hypotheses were presented, in order to individuate continuous and derivable interpolation lines for these set of points. The most proper opportunity was identified by using the Parametric Cubic Splines, that have all needed properties and can link the points as a curve "in pieces" formally defined.

With the aim to verify the efficacy of proposed method, it was tried with reference to two case studies regarding trajectories of vehicles over ramp terminals; these road elements were selected because of their geometrical and physical features that can particularly influence the users' behavior. The results show that the method seems very suitable for the proposed aims and, in particular, it can be integrated in automatic data processing of surveys over real-road operating conditions. In this way it will be possible to obtain a big amount of data, useful to study the relations between the hypothesis of theoretical design models and the experimental data obtained by road monitoring. This is, probably, the most promising opportunity in order to direct both the road design processes and the safety verifications of existing roads toward an innovative probabilistic approach.

\section{Acknowledgements}

Authors acknowledge data acquisition and early analyses of case studies, performed by Eng. L. Di Giampietro. 


\section{References}

AASHTO. (2001). Policy on Geometric Design of Highways and Streets. Washington, DC: American Association of State Highway and Transportation Officials, 1: 990.

Barsky, B. A., Bartels, R. H., \& Beatty, J. C. (1987). An Introduction to Splines for Use in Computer Graphics and Geometric Modeling. Los Altos, Calif.: M. Kaufmann Publishers.

Blana, E., \& Golias, J. (2002). Differences Between Vehicle Lateral Displacement on the Road and in a Fixed-Base Simulator. Human Factors: The Journal of the Human Factors and Ergonomics Society, 44(2), 303-313. http://dx.doi.org/10.1518/0018720024497899

Bonin, G., Cantisani, G., Loprencipe, G., \& Di Giampietro, L. (2003). Analisi Sperimentale Delle Traiettorie Veicolari Nelle Immissioni Ad Ago. In XIII Convegno Nazionale S.I.I.V. - Sessione A: Progettazione e Geometria. Padova: SIIV Società Italiana Infrastrutture Viarie.

Bonneson, J. A., Pratt, M., Miles, J., \& Carlson, P. (2007). Development of Guidelines for Establishing Effective Curve Advisory Speeds. Texas Transportation Institute, Texas A\&M University System. Retrieved from http://d2dt15nnlpfr0r.cloudfront.net/tti.tamu.edu/documents/0-5439-1.pdf

Cafiso, S., Di Graziano, A., \& La Cava, G. (2005). Actual Driving Data Analysis for Design Consistency Evaluation. Transportation Research Record: Journal of the Transportation Research Board, 1912, 19-30. http://dx.doi.org/10.3141/1912-03

Cantisani, G., \& Di Vito, M. (2012). CCV: A New Model for S85 Prediction. Procedia-Social and Behavioral Sciences, 53, 765-776. http://dx.doi.org/10.1016/j.sbspro.2012.09.926

Cantisani, G., Di Vito, M., \& Luteri, P. (2012). VPL Project'09: An Integrated Station for Vehicles' Operating Conditions Survey. Procedia-Social and Behavioral Sciences, 53, 777-788. http://dx.doi.org/10.1016/j.sbspro.2012.09.927

Cantisani, G., Dondi, D., Loprencipe, G., \& Ranzo, A. (2004). Spline Curves for Geometric Modeling of Highway Design. Proc., II Convegno Internazionale, SIIV: New Technologies and Modeling Tools For Road Applications to Design and Management.

Cantisani, G., Loprencipe, G., \& Primieri, F. (2011). The Integrated Design of Urban Road Intersections: A Case Study. In The International Conference on Sustainable Design and Construction 2011: ICSDC 2011: Integrating Sustainability Practices in the Construction Industry. pp. 722-728. http://dx.doi.org/10.1061/41204(426)88

Coifman, B., Beymer, D., McLauchlan, P., \& Malik, J. (1998). A Real-time Computer Vision System for Vehicle Tracking and Traffic Surveillance. Transportation Research Part C: Emerging Technologies, 6(4), 271-288. http://dx.doi.org/10.1016/S0968-090X(98)00019-9

De Luca, M., \& Dell'Acqua, G. (2012). Freeway Safety Management: Case Studies in Italy. Transport, 27(3), 320-326. http://dx.doi.org/10.3846/16484142.2012.724447

Dell'Acqua, G. (2012). European Speed Environment Model for Highway Design-Consistency. Modern Applied Science, 6(9), 1-10. http://dx.doi.org/10.5539/mas.v6n9p1

Di Mascio, P., Di Vito, M., Loprencipe, G., \& Ragnoli, A. (2012). Procedure to Determine the Geometry of Road Alignment Using GPS Data. Procedia-Social and Behavioral Sciences, 53, 1203-1216. http://dx.doi.org/10.1016/j.sbspro.2012.09.969

Fitzpatrick, K., Wooldridge, M. D., Tsimhoni, O., Collins, J. M., Green, P., Bauer, K. M., ... Anderson, I. (2000). Alternative Design Consistency Rating Methods for Two-lane Rural Highways. Retrieved from http://www.fhwa.dot.gov/publications/research/safety/ihsdm/99172/99172.pdf

Furtado, G. A., Easa, S. M., \& Abd El Halim, A. O. (2002). A Vehicle Stability on Combined Horizontal and Vertical Alignments. Carleton University. Retrieved from http://pedago.cegepoutaouais.qc.ca/media/0338252/a\%20supprimer/scgc/document/pdf/tr118-furtado.pdf

García, A., \& Romero, M. (2009). Discussion of 'Video-Capture-Based Approach to Extract Multiple Vehicular Trajectory Data for Traffic Modeling' by Heng Wei, Chuen Feng, Eric Meyer, and Joe Lee. Journal of Transportation $\quad$ Engineering, 135(3), 149-150. http://dx.doi.org/10.1061/(ASCE)0733-947X(2009)135:3(149)

Gibreel, G. M., Easa, S. M., Hassan, Y., \& El-Dimeery, I. A. (1999). State of the Art of Highway Geometric 
Design Consistency. Journal of Transportation Engineering, 125(4), $305-313$. http://dx.doi.org/10.1061/(ASCE)0733-947X(1999)125:4(305)

Giuliani, D. (2010). Comparison of Biological Shapes Using Extracted Edges Analyzed with Polynomial Hermite Interpolation. Modern Applied Science, 4(4), 3.

Glennon, J. C., \& Weaver, G. D. (1972). Highway Curve Design for Safe Vehicle Operations. Highway Research Record, 371.

Granà, A., Giuffrè, T., \& Marino, R. (2012). Researching a Capacity Model for Multilane Roundabouts with Negotiation of the Right-of-Way Between Antagonist Traffic Flows. Modern Applied Science, 6(5), 2-12. http://dx.doi.org/10.5539/mas.v6n5p2

Harlow, C., \& Peng, S. (2001). Automatic Vehicle Classification System with Range Sensors. Transportation Research Part C: Emerging Technologies, 231-247. http://dx.doi.org/10.1016/S0968-090X(00)00034-6

Hassan, Y. (2004). Highway Design Consistency: Refining the State of Knowledge and Practice.

Hauer, E. (2005). The Road Ahead. Journal of Transportation Engineering, 131(5), 333-339. http://dx.doi.org/10.1061/(ASCE)0733-947X(2005)131:5(333)

Hirsh, M. (1987). Probabilistic Approach to Consistency in Geometric Design. Journal of Transportation, 113(3), 268-276. http://dx.doi.org/10.1061/(ASCE)0733-947X(1987)113:3(268)

Hirsh, M., Prashker, J. N., \& Ben-Akiva, M. (1986). New Approach to Geometric Design of Highways. Transportation Research Record, 50-57.

IT, D. M. (2001). Norme Funzionali e Geometriche Per La Costruzione Delle Strade. (Italian Standard for Geometric and Functional Road Design) - D.M. 05/11/2001. Rome: Ministry of Infrastructures and Transportation.

Lamm, R., Choueiri, E. M., Hayward, J. C., \& Paluri, A. (1988). Possible Design Procedure to Promote Design Consistency in Highway Geometric Design on Two-lane Rural Roads. Transportation Research Record, 1195, 111-122.

Laparmonpinyo, P., \& Chitsobhuk, O. (2010). A Video-based Traffic Monitoring System Based on the Novel Gradient-edge and Detectionwindow Techniques. The 2nd International Conference. In Computer and Automation Engineering (ICCAE), 3, 30-34. http://dx.doi.org/10.1109/ICCAE.2010.5451846

Leisch, J. E., \& Leisch, J. P. (1977). New Concepts in Design-Speed Application. Transportation Research Record, 631. http://pubsindex.trb.org/view.aspx?id=71966

Mauro, R., \& Guerrieri, M. (2012). Right-turn Bypass Lanes at Roundabouts: Geometric Schemes and Functional Analysis. Modern Applied Science, 7(1), 1-12. http://dx.doi.org/10.5539/mas.v7n1p1

McLean, J. R. (1974). Driver Behaviour on Curves-a Review. In Australian Road Research Board (ARRB) Conference, Adelaide. Vol. 7.

Messer, C. J. (1980). Methodology for Evaluating Geometric Design Consistency. Transportation Research Record, 757.

Morris, B. T., \& Trivedi, M. M. (2008). Learning, Modeling, and Classification of Vehicle Track Patterns from Live Video. Intelligent Transportation Systems, IEEE Transactions, 9(3), 425-437. http://dx.doi.org/10.1109/TITS.2008.922970

Neuhardt, J. B., Herrin, G. D., \& Rockwell, T. H. (1971). Demonstration Of A Test-Driver Technique to Assess The Effects Of Roadway Geometrics And Development On Speed Selection.

Perco, P. (2008). Influence of the General Character of Horizontal Alignment on Operating Speed of Two-Lane Rural Roads. Transportation Research Record: Journal of the Transportation Research Board, 2075, 16-23. http://dx.doi.org/10.3141/2075-03

Reinfurt, D. W., Zegeer, C. V., Shelton, B. J., \& Neuman, T. R. (1991). Analysis of Vehicle Operations on Horizontal Curves. Transportation Research Record, 1318.

Semertzidis, T., Dimitropoulos, K., Koutsia, A., \& Grammalidis, N. (2010). Video Sensor Network for Real-time Traffic Monitoring and Surveillance. Intelligent Transport Systems, IET4(2), $103-112$. http://dx.doi.org/10.1049/iet-its.2008.0092 
Song, K. T., \& Tai, J. C. (2007). Image-based Traffic Monitoring with Shadow Suppression. Proceedings of the IEEE, 95(2), 413-426. http://dx.doi.org/10.1109/JPROC.2006.888403

Srinivasan, R., Torbic, D., Council, F., \& Harkey, D. (2009). Highway Safety Manual Knowledge Base. Retrieved from http://www.cmfclearinghouse.org/collateral/HSM_knowledge_document.pdf

TAC. (1999). Geometric Design Guide for Canadian Roads. Ottawa, Canada: Transportation Association of Canada.

VSS. (1991). Schweizer Norm SN 640-080-b, Projektierung Grundlagen-Geschwindigkeit Als Projektierungselement. Vereinigung Schweizerrischer Strassenfachleute, Zurich, Switzerland.

Wei, H., Feng, C., Meyer, E., \& Lee, J. (2005). Video-capture-based Approach to Extract Multiple Vehicular Trajectory Data for Traffic Modeling. Journal of Transportation Engineering, 131(7), 496-505. http://dx.doi.org/10.1061/(ASCE)0733-947X(2005)131:7(496)

Yu, X., Sulijoadikusumo, G., Li, H., \& Prevedouros, P. (2011). Reliability of Automatic Traffic Monitoring with Non-Intrusive Sensors. In Proceedings of Thellth International Conference of Chinese Transportation Professionals. http://dx.doi.org/10.1061/41186(421)414

\section{Copyrights}

Copyright for this article is retained by the author(s), with first publication rights granted to the journal.

This is an open-access article distributed under the terms and conditions of the Creative Commons Attribution license (http://creativecommons.org/licenses/by/3.0/). 